\title{
Análise de Correspondência entre Sexos na Percepção Ambiental dos Frequentadores de Parques Urbanos
}

Analysis of Correspondence Among Sexes in the Environmental Perception of Visitors in Urban Parks

Análisis de Correspondencia Entre Sexos en la Recepción de Frecuentadores de Parques Urbanos

Fabricio Camillo Sperandio Doutorando em Ciências Ambientais pela UNESP-Sorocaba, Brasil.

fabricioambiental@yahoo.com.br

Admilson Írio Ribeiro Docente da UNESP-Sorocaba, Brasil. admilson@sorocaba.unesp.br

Henrique Ewbank Professor colaborador da UNESP-Sorocaba, Brasil. henrique.ewbank@gmail.com

José Arnaldo Frutuoso Roveda Docente da UNESP-Sorocaba, Brasil. jose.roveda@unesp.br

Gerson Araújo de Medeiros Docente da UNESP-Sorocaba, Brasil. gerson@sorocaba.unesp.br 


\begin{abstract}
RESUMO
A ocupação do território, provocando o desequilíbrio ambiental, caracteriza-se de acordo com divergentes aspectos históricos, culturais e econômicos, que são capazes de originar condições singulares como as da conservação do ambiente natural e da degradação ambiental. Nesse contexto, o objetivo deste trabalho foi de avaliar as diferentes visões sobre as questões ambientais em um público heterogêneo de frequentadores de parques urbanos verificando o distanciamento das questões por meio do componente sexo. Para a análise da percepção ambiental foi utilizado um questionário hibrido do método survey com a escala likert, aplicado aos frequentadores do Parque Natural dos Esportes "Chico Mendes" em Sorocaba - estado de São Paulo, Brasil. As questões envolvidas tiveram premissa do discorrimento sobre o ambiente em três meios: antrópico, físico e biótico. Para a análise de dados foi utilizada a técnica multivariada de análise por correspondência, permitindo identificar a influência do sexo nas respostas do questionário. Dentre a percepção ambiental com a categoria de sexo, observam-se diversas conexões e semelhanças em suas respostas, mas os resultados obtidos também demonstraram uma variação da percepção entre os sexos em pelo menos uma das questões relacionadas aos três meios estudados. A pesquisa demonstrou que os homens são mais observadores do espaço e das características do parque. $O$ sexo feminino apresentou uma percepção mais sensível as questões ligadas a gestão do parque, e além disso, conseguiu identificar as preferências entre os ecossistemas que são encontrados nos parques urbanos.
\end{abstract}

PALAVRAS-CHAVE: Ocupação do território. Questionário de percepção. Parques públicos. Áreas verdes.

\begin{abstract}
Territorial occupation, leading to environmental imbalances, is characterized according to historical, cultural and economic aspects, which are capable of originating unique conditions, such as preservation of natural environments and environmental degradation. In this context, the objective of this study was to evaluate the different visions on environmental issues in a heterogeneous public of urban park visitors, verifying the distancing of the issues through the sex component. For the analysis of the environmental perception, a hybrid questionnaire of the survey method with the likert scale, applied to visitors of the "Chico Mendes" Sports Natural Park, on the city of Sorocaba, state of São Paulo, Southeast region of Brazil. Questions involved had the premise the discourse over three environments: anthropic, physical and biotic environments. For the data analysis, the multivariate technique of correspondence analysis was used, allowing the identification of sex influence in the questionnaire responses. Among the environmental perception with the category of sex, there are several connections and similarities in their responses, but the results obtained also demonstrated a variation of the perception between the genres in at least one of the questions related to the three environments studied. The search demonstrated that men are more observant of the space and features of the park. The female sex presented a more sensitive perception of the issues related to park management, and in addition, was able to identify the preferences among the ecosystems that are found in urban parks.
\end{abstract}

KEYWORDS: Territorial occupation. Perception questionnaire. Publics parks. Green areas.

\title{
RESUMEN
}

La ocupación del territorio, provocando el desequilibrio ambiental, se caracteriza de acuerdo con diversos aspectos históricos, culturales y económicos, que son capaces de originar condiciones singulares como las de conservación del ambiente natural e de la degradación ambiental. En este contexto, el objetivo de este trabajo fue el de evaluar las diferentes visiones sobre las cuestiones ambientales en un público heterogéneo de frecuentadores de parques urbanos verificando el distanciamiento de las cuestiones por medio del factor sexo. Para el análisis de la percepción ambiental fue utilizado un cuestionario hibrido del método de Survey con la escala de Likert, aplicado a los frecuentadores del Parque Natural de Deportes "Chico Mendes" en Sorocaba en el estado de São Paulo, Brasil. Las cuestiones envueltas, tuvieron premisa dl discurso sobre el ambiente en tres medios: Antrópico, Físico y Biótico. Para el análisis de datos fue utilizada la técnica multivariada de análisis por correspondencia, permitiendo identificar la influencia del factor sexo en las respuestas del cuestionario. Dentro de la percepción ambiental con la categoría de sexo, se observó diversas conexiones e semejanzas en sus respuestas, los resultados obtenidos también demostraron una variación de la percepción entre los sexos en por lo menos una de las cuestiones relacionados a los tres medios de estudiados. La investigación demostró que los hombres son más observadores del espacio y las características del parque, el sexo femenino presento una percepción más sensible a las cuestiones relacionadas a gestión del parque, e además de eso, conseguimos identificar las preferencias entre os ecosistemas que son encontradas en los parques urbanos.

PALABRAS CLAVE: Ocupación de territorio. Cuestionario de percepción. Parques públicos. Áreas verdes.

\section{INTRODUÇÃO}


Com o crescimento e a concentração das populações nas grandes cidades e o aumento continuo do consumo e de transformação de matérias primas em bens de consumo, a conservação do meio natural e o manejo dos recursos requer ações concretas para promoção de um meio ambiente ecologicamente equilibrado e a sua devida proteção como consta na constituição. Conforme o Art. 225. da Constituição Federal Brasileira de 1988. "Todos têm direito ao meio ambiente ecologicamente equilibrado, bem de uso comum do povo e essencial à sadia qualidade de vida, impondo-se ao Poder Público e à coletividade o dever de defendê-lo e preservá-lo para as presentes e futuras gerações" (BRASIL, 1988). Vicente-Molina et al. (2018), destaca que as sociedades modernas estão enfrentando questões sobre, consumo sustentável, conservação ambiental e de recursos naturais, etc., de modo que essas questões são úteis para ajudar formuladores de políticas públicas a exercerem estratégias mais efetivas a fim de encorajar homens e mulheres a se engajarem em práticas sustentáveis e diminuir as diferenças encontradas nos padrões de comportamento pró-ambientais.

Nesse cenário, diferentes comunidades percebem a preservação e conservação do meio ambiente de formas distintas. A ideia de preservação para uma comunidade indígena e rural, se apresenta muitas vezes diferente daquelas populações que vivem nos centros urbanos. Essas ideias estão associadas às percepções das comunidades dentro de seus sentidos e de vários aspectos socioculturais.

O entendimento da percepção da comunidade local sobre as áreas de Unidades de Conservação (UCs), pode auxiliar em uma tomada de decisão quanto às políticas de educação e conscientização ambiental. Os estudos e pesquisas sobre a percepção ambiental são importantes para obter informações sobre a população e a sua preferência e entendimento nas questões ambientais, pois cada indivíduo pensa e atua de forma única (COSTA \& COLESANTI, 2011).

Os estudos que tratam de específicos problemas ambientais, tendem a encontrar as maiores diferenças no componente sexo. Isso se estende para fatores que podem mediar o efeito do sexo na preocupação ambiental, como: o conhecimento científico / ambiental, as crenças e a religiosidade e a confiança nas instituições públicas (XIAO \& MCCRIGHT, 2015).

\section{OBJETIVOS}

\subsection{OBJETIVO GERAL}

O objetivo desse trabalho foi de identificar e demonstrar as diferenças nas percepções ambientais de frequentadores de parques urbanos através do componente sexo: feminino e masculino.

\subsection{OBJETIVOS ESPECÍFICOS:}

- Desenvolver um questionário para avaliar diferentes aspectos de nível ecológico;

- Identificar os padrões de correspondência entre os sexos;

- Avaliar as diferenças entre os sexos, a fim de melhorar nossa compreensão das suas particularidades;

- Identificar em quais relações os sexos variavam na percepção do espaço observado, em particular, demonstrar a importância do sexo para a interpretação do espaço geográfico e dos parques urbanos. 


\section{REFERENCIAL TEÓRICO}

\subsection{PARQUES URBANOS}

A utilização das áreas naturais para entretenimento ocorre a muito tempo, e tomou força especialmente no final do século XIX, quando o crescimento das cidades passou a se intensificar. A urbanização das cidades promoveu a valoração dos espaços rurais e dos ambientes naturais em busca de lazer, esporte, aprendizado, entre outras motivações. A visitação em áreas protegidas, muitas dessas inseridas no Sistema Nacional de Unidades de Conservação da Natureza (SNUC), (SNUC, Lei $n$. o 9.985, de 18 de julho de 2000), pode ser entendida como atividades educativas, recreativas e de interpretação ambiental, que propiciam ao visitante a oportunidade de conhecer, entender e valorizar os recursos naturais e culturais dessas áreas (BRASIL, 2009).

$\mathrm{O}$ interesse da população em procurar os parques urbanos, acarreta em uma maior atenção aos espaços verdes presentes nos meios urbanos e peri-urbanos, e a frequência de visitação nos parques e áreas verdes refletem na qualidade de vida da população (CONEDERA et al., 2015).

Com isso, a qualidade ambiental urbana está ligada ao acesso dos moradores à qualidade, quantidade e distribuição de espaços verdes nos quais possam interagir com a natureza, proporcionando possibilidades de lazer e socialização. A preservação e conservação do meio natural, necessita de áreas protegidas e parques, onde esses locais disponibilizam para a população áreas para a recreação, relaxamento e contato com a natureza (RICHTER \& BÖCKER, 1998; PINA \& DOS SANTOS, 2009).

Da Silva \& Soriano-Sierra (2015), argumentam que, as questões ambientais e os processos de avaliação e verificação das condições dos parques públicos legitimam a legislação ambiental. Para garantir isso, torna-se necessário que os municípios desenvolvam ações de planejamento e gestão, com base no conhecimento da população local para atender os princípios da sustentabilidade.

\subsection{PERCEPÇÃO AMBIENTAL}

A percepção ambiental tem se tornado uma ferramenta bastante aplicada e importante para os estudos que consideram as relações entre meio ambiente e as atuações humanas como sendo uma forma de analisar as atitudes e valores, que são os principais formadores da topofilia (elo afetivo entre a pessoa e o lugar), onde isso acaba refletindo em ações de conservação (DE LUCENA \& FREIRE, 2011). As pesquisas na percepção ambiental propõem que não somente a relação entre homem e meio ambiente seja avaliada, mas também que aspectos de pesquisas científicas, sociais ou políticas sejam explicadas, promovendo a sensibilização e compreensão do meio ambiente a partir de um sistema de percepção (RODRIGUES et al., 2012).

Elali (2009), explica que embora a percepção ambiental deva ser compreendida como um modo de perceber como as pessoas interpretam o meio ambiente, não pode ser encarada como uma forma principal. A percepção ambiental serve também para nos mostrar onde pode ser focado estudos mais complexos de consciência do ser humano.

Compreender a percepção das pessoas sobre os impactos e a importância da conservação ambiental torna-se fundamental para a consciência política, porque define e expõe os contextos sociopolíticos locais e globais. Para isto fica necessário apresentar uma abordagem para extrair e comparar o "conhecimento" sobre a percepção ambiental (CRONA et al., 2013). 


\subsection{PERCEPÇÃO AMBIENTAL E O COMPONENTE GÊNERO}

O termo gênero apareceu pela primeira vez na literatura médica e biológica na década de 1960 em publicações de pesquisas sobre a psicologia individual. As pesquisas não se referem apenas a diferenças entre masculino e feminino, mas também diferenças entre as culturas (PARDUE, 2001).

Na gramática, gênero é um preceito de designação do feminino e do masculino. As convenções sociais desempenhadas por cada sexo influenciam em suas preferências, atitudes e valores, sendo estes, componentes presentes nas percepções. A partir da percepção ambiental e a construção social dos indivíduos, considera-se o conceito de gênero um importante fator de uma pesquisa (MORAES, 2012). Coluccia \& Louse (2004), discorrem em sua pesquisa, que embora haja diferenças significativas sobre influências de fatores biológicos e socioculturais, são discutidos a hipótese de que os gêneros também se diferem nas estratégias utilizadas de orientação espacial, caso contrário, estudos com abordagens ecológicas não mostrariam diferenças marcantes de gênero.

Weiss (2003), em seu trabalho sobre as funções cognitivas entre os gêneros destaca que os homens se diferenciam das mulheres em testes de raciocínio de ciências exatas e orientações espaciais. As mulheres exibem maior flexibilidade nas tarefas linguísticas, com isso, tendem a ser melhores em fluência verbal, articulação da fala e habilidades gramaticais.

Uma das finalidades das pesquisas sobre o gênero consiste em estar investigando as habilidades visuoespaciais dos padrões de desempenho entre homens e as mulheres que poderiam resultar em minimizar as diferenças cognitivas globais (BOSCO et al.,2004).

Assim, um número crescente de estudos científicos descrevem abordagens baseadas em sistemas para avaliar a relação entre gênero, percepção ambiental e culturas que reconhecem as diferenças por gênero, como descrito por Brisolara (2014).

Mulheres e homens frequentemente têm interesses diferenciados e obtêm dimensões diferentes do meio ambiente, portanto, a percepção e conhecimento dos serviços ecossistêmicos também diferem. Compreender essas diferenças, consiste em garantir que as políticas destinadas a melhorar o acesso e o uso de serviços ecossistêmicos possam trazer benefícios para todos os gêneros (YANG, 2018).

\subsection{A ANÁLISE DE CORRESPONDÊNCIA}

A análise de correspondência pode ser utilizada em trabalhos com variáveis qualitativas (ou dados categóricos), e fornece as coordenadas para as linhas e as colunas da tabela de contingência. Essas coordenadas são usadas para visualizar graficamente a associação entre as variáveis de linha e coluna na tabela de contingência (STHDA, 2017).

Fundamentalmente em uma tabela de contingência cada célula informa o agrupamento, número de objetos ou de indivíduos que pertencem ou escolheram aquela combinação de categorias, agrupando o número das respostas fornecendo assim a sua concentração de respostas, e auxiliando na sua visualização (SILVA, 2012).

A proximidade das respostas traduz graficamente o fato observado onde as respostas apresentam em número suficientemente grande de semelhanças nas respostas estudadas. Considerando a contingência, a distância usada para avaliar a semelhança entre as linhas e as colunas, cresce na medida em que aumenta as respostas diferentes que esses indivíduos apresentam. Dentre os objetivos da análise de correspondência esta as relações que podem existir entre os indivíduos e/ou entre eles e as categorias avaliadas. Para que se possa efetuar a comparação desejada, fica necessário que se 
faça uma representação gráfica das bases de observação para promover a construção das tipologias dos indivíduos (ALVES \& FERNANDES \& DOS REIS, 2009).

As fases envolvidas na computação da análise de correspondência bem como os resultados relacionados, ocorre principalmente no programa R. A questão correspondente ativa ou complementa um certo número de categorias de resposta (NENADIC \& GREENACRE, 2005).

\section{METODOLOGIA}

\subsection{DESCRIÇÕES DA ÁREA DE ESTUDO}

O Parque Natural dos Esportes "Chico Mendes", é a terceira maior área de preservação de Sorocaba, estado de São Paulo, e administrado pela prefeitura. O parque possui uma área verde de 15,6 ha, localizado nas coordenadas $23 \circ 28$ '33" S e 47024 ' $44^{\prime \prime} \mathrm{W}$ a $600 \mathrm{~m}$ de altitude em média, com cobertura de mata atlântica natural, enriquecida com eucaliptos, plantas ornamentais, lagos e trilhas para atividades educativas (FIGURA 1).

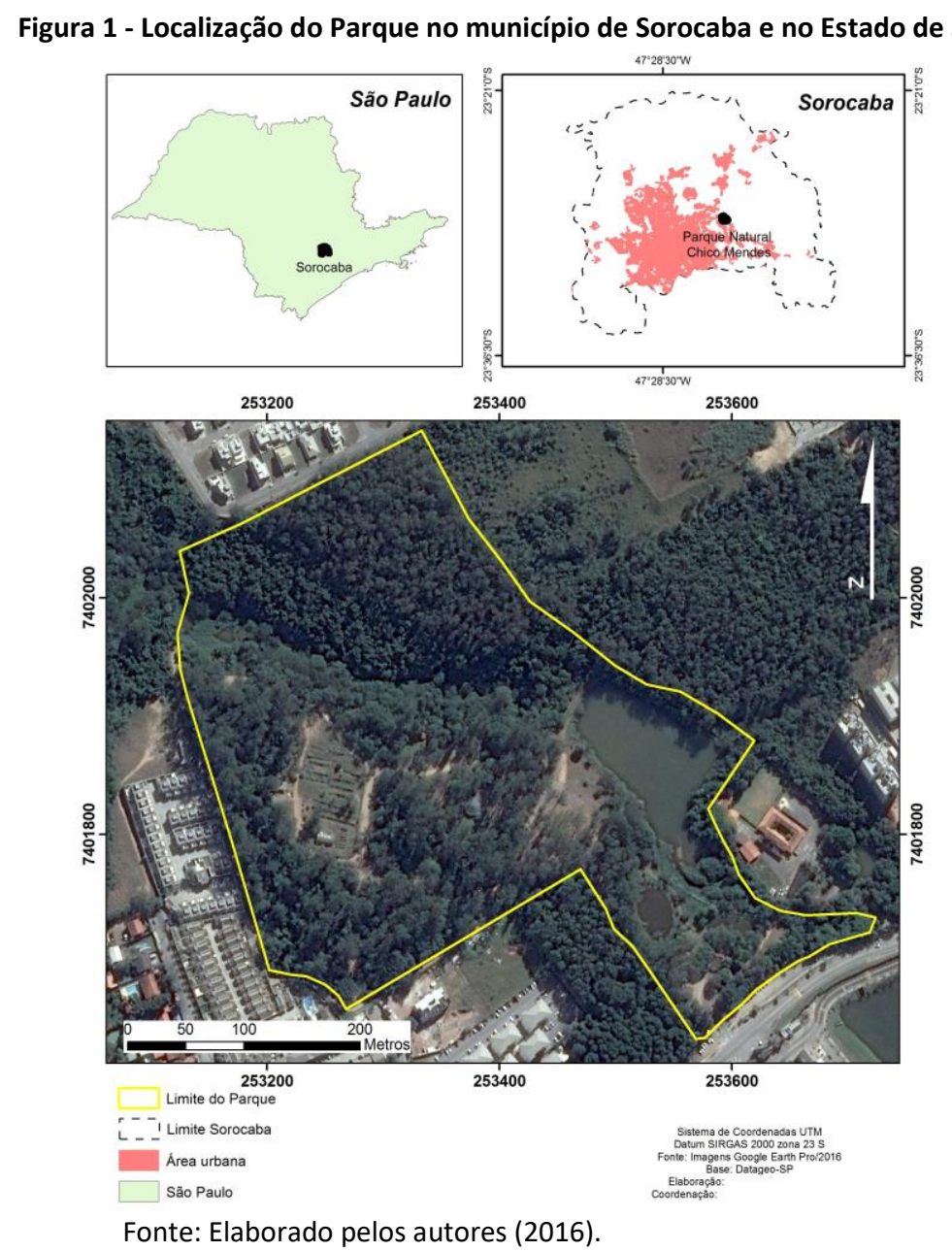

\subsection{METODOLOGIA DE CONSTRUÇÃO DO QUESTIONÁRIO A SER APLICADO E ÉTICA DA PESQUISA}

Essa construção ou fundamentação se fez com o desenvolvimento de uma pesquisa do método Survey e utilizando em algumas questões a escala Likert, sendo esta mais utilizada em levantamento de 
opiniões e avaliações, onde se predispõem ao entrevistado alternativas numa construção progressiva de respostas (JABBOUR \& SANTOS \& NAGANO, 2009).

A aplicação do questionário seguiu algumas regras como: não necessitar da identificação dos entrevistados; não abordar ou recolher o questionário junto a menores de idade ou com algo que os deixem em situação de vulnerável.

O questionário proposto (QUADRO 1), foi elaborado com base nas questões principais relativas à área de preservação, e ao modo que as pessoas veem e interagem com os meios antrópico, físico e biótico. Por fim as questões relativas ao perfil sócio demográfico dos usuários.

Quadro 1 - Questões aplicadas relativas aos meios de interesse perceptíveis dos frequentadores do Parque Chico Mendes.

\begin{tabular}{|c|c|c|c|}
\hline Meio antrópico & Meio físico & Meio biótico & $\begin{array}{l}\text { Sócio demográfico } \\
\text { Perfil }\end{array}$ \\
\hline $\begin{array}{l}\text { 1. Você possui alguma } \\
\text { formação na questão } \\
\text { ambiental? } \\
\text { a. Não obtive em } \\
\text { nenhuma parte da minha } \\
\text { formação } \\
\text { b. Apenas no ensino } \\
\text { Fundamental } \\
\text { c. Apenas no ensino } \\
\text { Médio } \\
\text { d. Apenas no ensino } \\
\text { Superior } \\
\text { e. Informal }\end{array}$ & $\begin{array}{l}\text { 6. Você considera o } \\
\text { córrego e os lagos do } \\
\text { Parque Chico Mendes } \\
\text { importantes para você? } \\
\text { a. Sim } \\
\text { b. Não tem uma opinião } \\
\text { sobre o assunto } \\
\text { c. Não }\end{array}$ & $\begin{array}{l}\text { 13. Você considera a } \\
\text { vegetação do Parque } \\
\text { importante para quem o } \\
\text { frequenta? } \\
\text { a. Sim } \\
\text { b. Não sabe responder } \\
\text { c. Não }\end{array}$ & $\begin{array}{l}\text { 19. Gênero? } \\
\text { a. Masculino } \\
\text { b. Feminino }\end{array}$ \\
\hline $\begin{array}{l}\text { 2. Você considera os } \\
\text { Parques, espaços } \\
\text { importantes para a } \\
\text { socialização nas cidades? } \\
\text { a. Sim } \\
\text { b. Não sabe informar } \\
\text { c. Não } \\
\text { d. Indiferente }\end{array}$ & $\begin{array}{l}\text { 7. Na sua opinião qual é a } \\
\text { qualidade da água do } \\
\text { córrego e dos lagos no } \\
\text { Parque? } \\
\text { a. Ótima } \\
\text { b. Boa } \\
\text { c. Regular } \\
\text { d. Ruim } \\
\text { e. Péssima }\end{array}$ & $\begin{array}{l}\text { 14. Em sua opinião, a } \\
\text { quantidade e o aspecto } \\
\text { da vegetação do Parque, } \\
\text { apresentam-se em que } \\
\text { estado? } \\
\text { a. Ótimo } \\
\text { b. Bom } \\
\text { c. Regular } \\
\text { d. Ruim } \\
\text { e. Péssimo }\end{array}$ & $\begin{array}{l}\text { 20. Estado civil? } \\
\text { a. Solteiro } \\
\text { b. Casado } \\
\text { c. Viúvo } \\
\text { d. Outro }\end{array}$ \\
\hline $\begin{array}{l}\text { 3. A quem você atribui a } \\
\text { responsabilidade da } \\
\text { conservação do Parque? } \\
\text { a. Órgãos do governo } \\
\text { b. Comunidade } \\
\text { c. Turistas } \\
\text { d. Estudantes que } \\
\text { frequentam os cursos em } \\
\text { educação ambiental } \\
\text { e. Funcionários do parque } \\
\text { f. Todos acima }\end{array}$ & $\begin{array}{l}\text { 8. Dentro do Parque } \\
\text { Chico Mendes você } \\
\text { considera que as } \\
\text { estradas, trilhas e } \\
\text { espaços abertos atendem } \\
\text { a necessidade dos } \\
\text { frequentadores? } \\
\text { a. Sim } \\
\text { b. Não sabe responder } \\
\text { c. Não }\end{array}$ & $\begin{array}{l}\text { 15. Você definiria a } \\
\text { vegetação existente no } \\
\text { Parque, sendo? } \\
\text { a. De mata atlântica } \\
\text { b. De espécies exóticas } \\
\text { c. De savana (cerrado) } \\
\text { d. Está entre mata } \\
\text { atlântica e espécies } \\
\text { exóticas } \\
\text { e. Está entre mata } \\
\text { atlântica e cerrado } \\
\text { f. Está entre vegetação } \\
\text { mata atlântica, espécies } \\
\text { exóticas e cerrado }\end{array}$ & $\begin{array}{l}\text { 21. Idade? } \\
\text { a. De18 a } 24 \text { anos } \\
\text { b. De } 25 \text { a } 34 \text { anos } \\
\text { c. De } 35 \text { a } 45 \text { anos } \\
\text { d. De } 46 \text { a } 59 \text { anos } \\
\text { e. Mais de } 60 \text { anos }\end{array}$ \\
\hline $\begin{array}{l}\text { 4. O que você considera } \\
\text { como dano ambiental } \\
\text { negativo no Parque? } \\
\text { a. Danos relativos a festas } \\
\text { e churrascos } \\
\text { b. Produção de lixo }\end{array}$ & $\begin{array}{l}\text { 9. Na sua opinião ocorre } \\
\text { processos erosivos nas } \\
\text { estradas, trilhas e } \\
\text { espaços abertos do } \\
\text { Parque? } \\
\text { a. Não ocorre processo } \\
\text { erosivo }\end{array}$ & $\begin{array}{l}\text { 16. Você acha que a fauna } \\
\text { urbana e local são } \\
\text { importantes para o } \\
\text { Parque? } \\
\text { a. Sim } \\
\text { b. Não sabe responder } \\
\text { c. Não }\end{array}$ & $\begin{array}{l}\text { 22. Escolaridade? } \\
\text { a. Ensino Fundamental } \\
\text { b. Ensino Médio } \\
\text { c. Ensino Superior } \\
\text { d. Especialização } \\
\text { e. Mestrado } \\
\text { f. Doutorado }\end{array}$ \\
\hline
\end{tabular}




\begin{tabular}{|c|c|c|c|}
\hline $\begin{array}{l}\text { c. O ambiente prejudicado } \\
\text { com muitas pessoas } \\
\text { d. Ação de vandalismo } \\
\text { e. Falta de fiscalização }\end{array}$ & $\begin{array}{l}\text { b. Há um processo brando } \\
\text { de erosão } \\
\text { c. Sim, há um processo } \\
\text { severo de erosão } \\
\text { d. Sim, há processos } \\
\text { muito severos de erosão } \\
\text { e. Não tem uma opinião } \\
\text { sobre o assunto }\end{array}$ & & \\
\hline \multirow[t]{3}{*}{$\begin{array}{l}\text { 5. O que você acha do } \\
\text { trabalho do Parque em } \\
\text { relação aos programas } \\
\text { educativos relacionados } \\
\text { com a conservação da } \\
\text { natureza? } \\
\text { a. Muito bom } \\
\text { b. Bom } \\
\text { c. Razoável } \\
\text { d. Não se interessa } \\
\text { e. Não tem uma opinião } \\
\text { sobre o assunto }\end{array}$} & $\begin{array}{l}\text { 10. Você considera o } \\
\text { relevo e as características } \\
\text { deste Parque sendo? } \\
\text { a. Considero plano } \\
\text { b. Ondulado } \\
\text { c. Alto } \\
\text { d. Baixo } \\
\text { e. Acidentado } \\
\text { f. Com outras feições }\end{array}$ & $\begin{array}{l}\text { 17. Qual tipo de fauna } \\
\text { você acha que ocorre } \\
\text { com mais frequência no } \\
\text { Parque? } \\
\text { a. Avifauna (Pássaros) } \\
\text { b. Herpetofauna (Répteis } \\
\text { e Anfíbios) } \\
\text { c. Mastofauna } \\
\text { (Mamíferos) } \\
\text { d. Ictiofauna (Peixes) } \\
\text { e. Não sabe responder }\end{array}$ & $\begin{array}{l}\text { 23. Renda mensal } \\
\text { individual: } \\
\text { a. Até } R \$ 1000,00 \\
\text { b. De } 1.000 \text { a } 2.000 \\
\text { c. De } 2.000 \text { a } 4.000 \\
\text { d. De } 4.000 \text { a } 6.000 \\
\text { e. Acima de } 6.000\end{array}$ \\
\hline & $\begin{array}{l}\text { 11. Você considera a } \\
\text { qualidade do ar relevante } \\
\text { na sua visita ao Parque } \\
\text { Chico Mendes? } \\
\text { a. Sim } \\
\text { b. Não sabe responder } \\
\text { c. Não }\end{array}$ & $\begin{array}{l}\text { 18. Dentro dos } \\
\text { ecossistemas do Parque } \\
\text { qual chama mais a sua } \\
\text { atenção? } \\
\text { a. Ecossistemas terrestres } \\
\text { b. Ecossistemas aquáticos } \\
\text { c. Ecossistemas de } \\
\text { interfaces } \\
\text { d. Todos } \\
\text { e. Não sabe responder }\end{array}$ & \\
\hline & $\begin{array}{l}\text { 12. Na sua opinião qual é } \\
\text { a qualidade do ar no } \\
\text { Parque Chico Mendes? } \\
\text { a. Ótima } \\
\text { b. Boa } \\
\text { c. Regular } \\
\text { d. Ruim } \\
\text { e. Péssima }\end{array}$ & & \\
\hline
\end{tabular}

Fonte: Elaborado pelos autores (2016).

O questionário foi submetido ao CEP (Comitê de Ética em Pesquisa), e foi aplicado após a sua aprovação. $\mathrm{O}$ mesmo foi aplicado em dias comerciais e também em dois finais de semana para se encontrar uma maior diversidade de frequentadores no parque.

\subsection{DEFINIÇÃO DO TAMANHO DA AMOSTRA DO QUESTIONÁRIO APLICADO}

Contando com uma média de 6.500 visitantes por mês registrados na catraca de entrada, mas observando a frequência com que as pessoas entram e saem, seja para ir buscar algo em seus veículos ou mesmo os funcionários do parque, estimou-se uma média mensal de 2000 pessoas que acessam o local. A coleta do questionário foi feita no período de 30 de novembro a 14 de dezembro de 2016.

Para se chegar ao número de pessoas a serem entrevistadas (tamanho amostral), utilizou se de um universo de 1000 possíveis frequentadores que se refere aos 15 dias de entrevistas no campo. Dessa maneira, se fez um cálculo para esta pesquisa onde foi identificada a necessidade de entrevistar 131 pessoas para se alcançar $95 \%$ de confiança. Sendo assim, ao termino da aplicação do questionário conseguiu-se 134 questionários respondidos, e esta pesquisa exigiu uma margem de erro de $8 \%$. 


\subsection{MÉTODO DE ANÁLISE DOS DADOS}

Os dados (respostas) foram tabulados em planilha eletrônica no software Microsoft Office Excel e através do Software $\mathrm{R}$ pôde se fazer a tabela de contingência e posteriormente realizar o teste chiquadrado para avaliar a significância desta associação entre as variáveis, o que valida estar implícito o teste de análise de correspondência.

Nesse escopo, a análise da correspondência é uma extensão da PCA (Análise de Componentes Principais), adequada para analisar uma grande tabela de contingência formada por duas variáveis qualitativas ou de dados categóricos. Consiste em uma técnica geométrica para exibir as características de linhas e colunas com objetivo de ter uma visão global dos dados que seja útil para a interpretação. Para conseguir realizar as análises dos dados com o Software $R$, foi necessário a utilização de dois pacotes, que são:

- O gplots foi utilizado para interpretar facilmente a tabela de contingência, uma matriz gráfica que pôde ser desenhada usando a função balloonplot, onde neste gráfico cada célula contém um ponto cujo tamanho reflete as ocorrências de respostas (STHDA, 2017);

- O factoextra foi utilizado por facilitar a extração e visualização do resultado das análises exploratórias de dados multivariados, incluindo a análise de correspondência (KASSAMBARA \& MUNDT, 2017).

\section{RESULTADOS E DISCUSSÕES}

\subsection{ANÁLISE DE CORRESPONDÊNCIA ENTRE OS SEXOS E AS QUESTÕES RELACIONADAS AO MEIO ANTRÓPICO.}

A Figura 2, apresenta a tabela de contingência entre as respostas do sexo dos entrevistados e as questões relacionadas ao meio antrópico. Observam-se dois pontos de maior frequência de ocorrência sendo esse definido pelas questões P2 que apresenta maior frequência de resposta 1 (a) para os sexos masculinos e feminino na questão, e na P3 a resposta 6 (f) para ambos os sexos.

Figura 2 - Tabela de contingência entre as respostas dos entrevistados e as questões relacionadas ao meio antrópico.

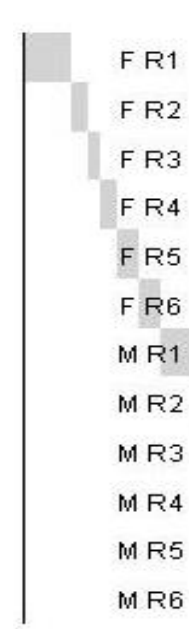

\begin{tabular}{|c|c|c|c|c|}
\hline P.1 & P. 2 & P.3 & P. 4 & P.5 \\
\hline$\circ$ & 0 & 은 & $=$ & 8 \\
\hline$\bullet$ & & * & $\ominus$ & 룽 \\
\hline 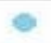 & & & . & e \\
\hline e & & & 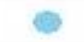 & \\
\hline e & & - & 8 & $\cdot$ \\
\hline & & & & \\
\hline 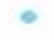 & 0 & 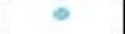 & - & . \\
\hline - & & * & e & e \\
\hline - & & . & - & - \\
\hline e & & & 은 & \\
\hline e & & + & 앙 & 0 \\
\hline & & 8 & & \\
\hline
\end{tabular}

Fonte: Elaborado pelos autores (2018).

Legenda: F: (Feminino); M: (Masculino); R: (Resposta); R1 (a); R2 (b); R3 (c); R4 (d); R5 (e); R6 (f). 
De acordo com a TABELA 1 os autovalores das principais dimensões são:

Tabela 1 - Principais dimensões e suas inércias (autovalores) para a interação sexo e questões do meio Antrópico.

\begin{tabular}{cccc}
\hline $\operatorname{dim}$ & Autovalor & \multicolumn{1}{c}{$\%$} & acum \% \\
1 & 0.73842510 & 49.9 & 49.9 \\
2 & 0.56547295 & 38.2 & 88.1 \\
3 & 0.09754921 & 6.6 & 94.7 \\
4 & 0.07836368 & 5.3 & 100.0 \\
& & \\
\hline \multicolumn{4}{c}{ Inercia total -----1.479811 } \\
\end{tabular}

Fonte: Elaborado pelos autores (2018).

Considerando a variação total do sistema explicada em $88.1 \%$ pelas duas dimensões principais foi possível construir o gráfico de correspondência. A estatística chi-quadrado foi de 991.47 indicando uma associação entre as linhas (sexo e respostas), com as colunas estabelecidas do meio antrópico. Observa-se no gráfico de correspondência (FIGURA 3), que a questão P3 (A quem você atribui a responsabilidade da conservação do Parque?), tem correspondência com a resposta $R 6$ (f), que está associada a todos os envolvidos que são: órgãos do governo, comunidade, turistas, estudantes que frequentam os cursos em educação ambiental e os funcionários do parque. A questão P2 (Você considera os Parques, espaços importantes para a socialização nas cidades?), apresenta uma correspondência maior com a resposta R1 (sim). As outras questões apresentam uma maior diversidade de respostas.

Figura 3 - Gráfico de correspondência entre linhas (sexo) com as colunas questões estabelecidas para o meio antrópico.

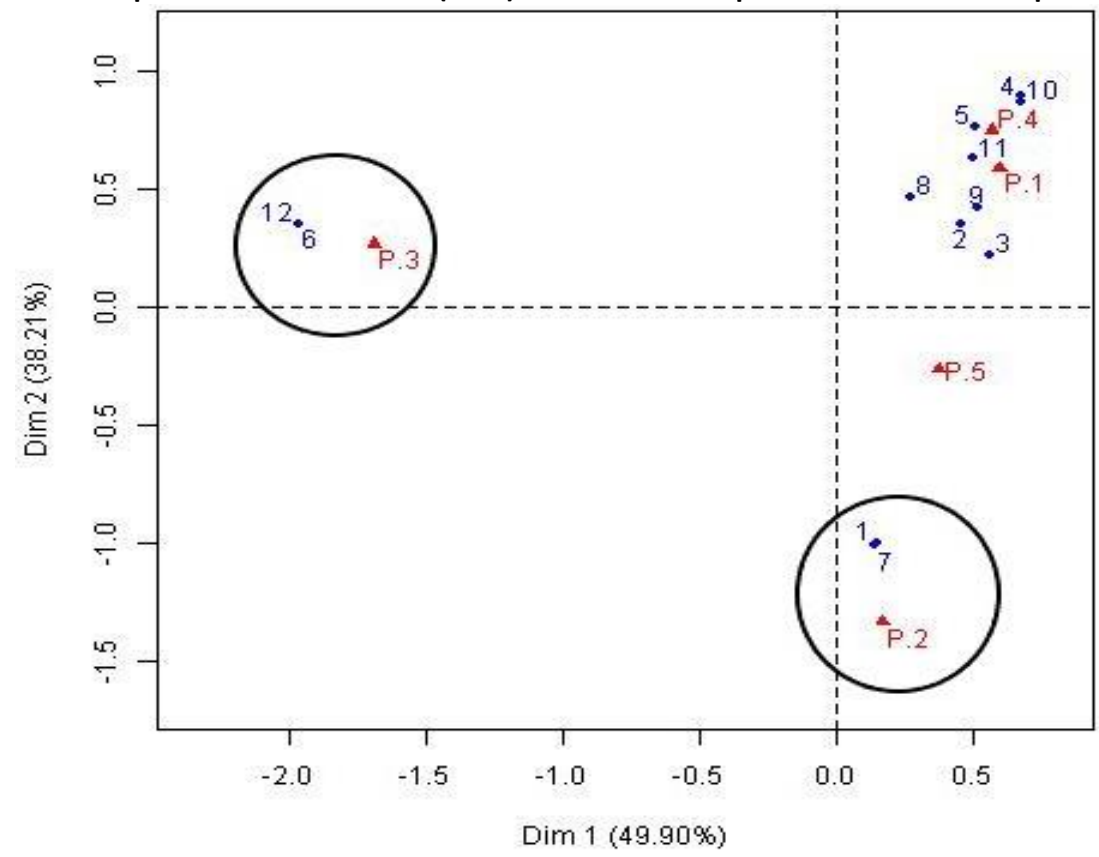

Fonte: Elaborado pelos autores (2018).

Legenda: P: (Pergunta); 1 a 6 (Sequência de respostas Feminina); 7 a 12 (Sequência de respostas Masculina). 
As perguntas P1 (Você possui alguma formação na questão ambiental?), e P5 (O que você acha do trabalho do Parque em relação aos programas educativos relacionados com a conservação da natureza?), apresentaram uma maior diversidade de resposta, mas ambos os sexos em sua maioria responderam terem visto sobre as questões ambientais no ensino superior, e na questão P5, a maioria entre os sexos acreditam ser muito bom os programas educativos do parque.

A questão P4 (O que você considera como dano ambiental negativo no Parque?), a maioria das mulheres acreditam que a falta de fiscalização (presença física), mesmo não sendo um dano negativo acaba mostrando a tendência de o sexo feminino ser mais sensível a gestão, enquanto os homens acreditaram, em sua maioria, que seja a produção de lixo pelos frequentadores.

Yang (2018), destacou que as mulheres tinham um maior interesse do que os homens, pelas prestações de serviços em ambientes públicos (gestão do parque), onde também inclui a fiscalização. Os homens demonstraram que a poluição visual como o lixo e odores sentidos nos parques era o que mais incomodava nas suas visitas.

Na pesquisa de Sneider et al. (2015), desde a infância, as crianças têm a capacidade de localizar informações básicas com base na relação entre uma observação e as características ambientais. A autora constatou que os homens têm uma maior preferência para uma estratégia de orientação de exploração em relação às mulheres que relataram preferência por uma estratégia de sinais ou indicações de outras pessoas. Garcia-Cervantes et al. (2015), ainda afirma em sua pesquisa, que os meninos são mais ativos que as meninas, e apresentam maiores índices de percepção ambiental.

\subsection{ANÁLISE DE CORRESPONDÊNCIA ENTRE OS SEXOS E AS QUESTÕES RELACIONADAS AO MEIO FÍSICO.}

A FIGURA 4 apresenta a tabela de contingência entre as respostas do sexo dos entrevistados e as questões relacionadas ao meio físico. Destaca-se as respostas R1 nas questões P6, P8 e P11.

Figura 4 - Tabela de contingência entre as respostas dos entrevistados e as questões relacionadas ao meio físico.

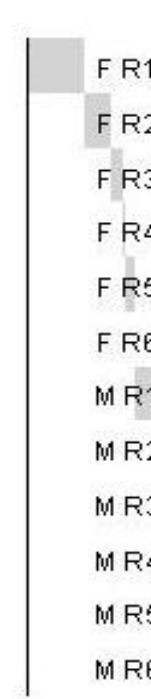

\begin{tabular}{|c|c|c|c|c|c|c|}
\hline \multirow[t]{2}{*}{ P.6 } & P. 7 & \multicolumn{2}{|c|}{ P. 8.9} & P.10 & P.11 & P.12 \\
\hline & - & 8 & - & (1) & 0 & P \\
\hline & O & & e & 8 & & (2) \\
\hline$\bullet$ & (1) & - & 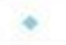 & & . & . \\
\hline & - & & . & 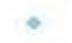 & & . \\
\hline - & & $=$ & P & ? & & \\
\hline & & & & . & & \\
\hline 0 & . & Q & - & 하임 & 0 & (-) \\
\hline & 웅 & & 임 & (2) & & e \\
\hline$\bullet$ & C & $\bullet$ & $\circ$ & . & . & . \\
\hline & - & & * & - & & \\
\hline & & 항 & 붕 & • & & \\
\hline & & & & - & & \\
\hline
\end{tabular}

Fonte: Elaborado pelos autores (2018).

Legenda: F: (Feminino); M: (Masculino); R: (Resposta); R1 (a); R2 (b); R3 (c); R4 (d); R5 (e); R6 (f). 
De acordo com a TABELA 2 os autovalores das principais dimensões são:

Tabela 2 - Principais dimensões e suas inércias (autovalores) para a interação sexo e questões meio Físico.

\begin{tabular}{cccc}
\hline $\operatorname{dim}$ & Autovalor & $\%$ & acum\% \\
1 & 0.4692858559 & 59.2 & 59.2 \\
2 & 0.1668177363 & 21.0 & 80.3 \\
3 & 0.1150848312 & 14.5 & 94.8 \\
4 & 0.0306954076 & 3.9 & 98.6 \\
5 & 0.0101501124 & 1.3 & 99.9 \\
6 & 0.0005031002 & 0.1 & 100.0 \\
\hline \multicolumn{5}{c}{ Inercia total----0.792537 } \\
\hline
\end{tabular}

Fonte: Elaborado pelos autores (2018).

Considerando a variação total do sistema explicada em $80.3 \%$ pelas duas dimensões principais foi possível construir o gráfico de correspondência. A estatística chi-quadrado foi de 743.4 indicando uma associação entre as linhas (sexos e respostas) com as colunas estabelecidas para o meio físico.

Observa-se no gráfico de correspondência (FIGURA 5), que as perguntas P6 (Você considera o córrego e os lagos do Parque Chico Mendes importantes para você?); P11 (Você considera a qualidade do ar relevante na sua visita ao Parque Chico Mendes?) e P8 (Dentro do Parque Chico Mendes você considera que as estradas, trilhas e espaços abertos atendem a necessidade dos frequentadores?) apresentaram correspondências semelhantes em relação a respostas a (R1), para ambos os sexos. As outras questões apresentam uma maior diversidade de respostas.

Figura 5 - Gráfico de correspondência entre linhas (sexo) com as colunas questões estabelecidas para o meio Físico.

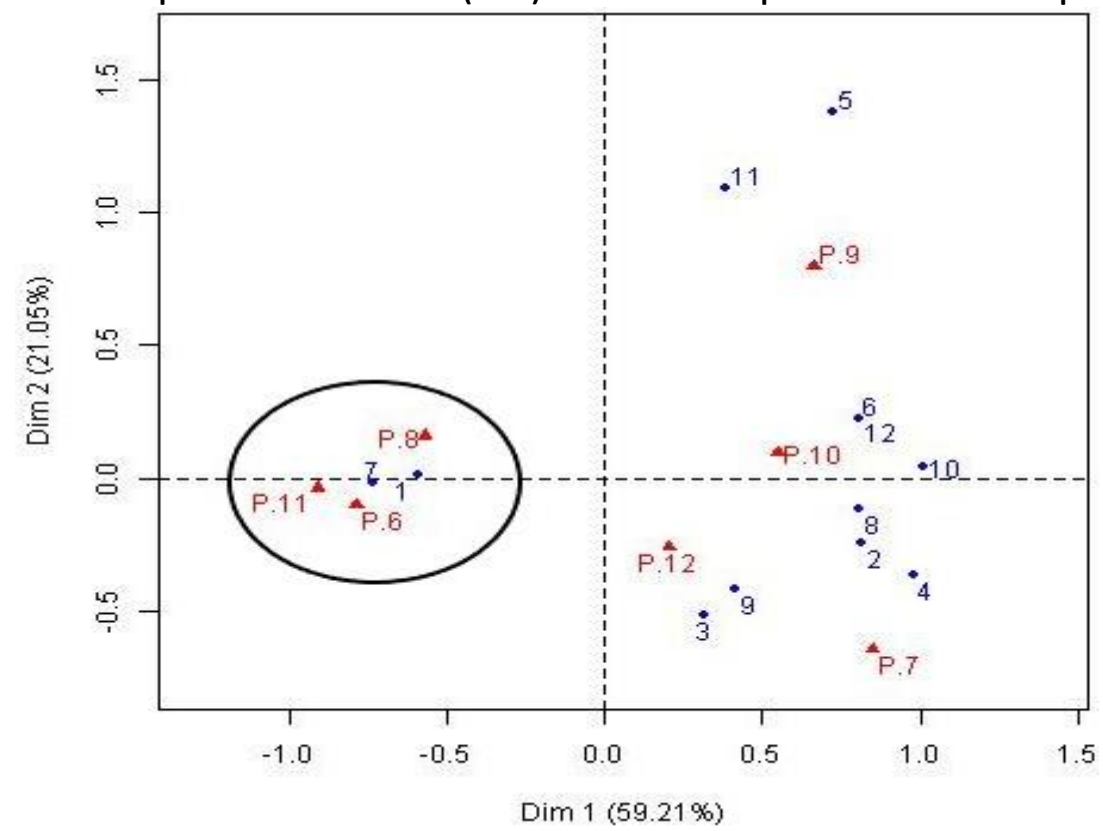

Fonte: Elaborado pelos autores (2018).

Legenda: P: (Pergunta); 1 a 6 (Sequência de respostas Feminina); 7 a 12 (Sequência de respostas Masculina). 
A questão P7 (Na sua opinião qual é a qualidade da água do córrego e dos lagos no Parque?), mesmo tendo uma grande diversidade de respostas, tanto os homens quanto as mulheres em sua maioria acreditam que a qualidade da água está boa. Todavia, estudos conduzidos de qualidade da água nos lagos do Parque Chico Mendes apontaram um estado supereutrófico devido a elevados teores de fósforo (DE CARLI et al., 2014a), provavelmente por lançamento de esgoto, o que foi corroborado pela presença de organismos bentônicos característicos de ambiente poluído (DE CARLI et al., 2014b) e pela comunidade fitoplanctonica observada nesse local (SANTOS et al., 2014).

Na maioria dos estudos revisados por Yang (2018), as mulheres apontaram uma maior importância em suas respostas na preocupação com a qualidade da água e mostraram um conhecimento maior neste assunto. Xiao (2015), constatou em sua pesquisa, que as mulheres relataram percepções ambientais em maiores níveis de preocupação com os problemas ambientais em comparação aos homens.

A questão P9 ( $N a$ sua opinião ocorre processos erosivos nas estradas, trilhas e espaços abertos do Parque?), a maioria das respostas do sexo feminino responderam que não tem uma opinião sobre o assunto, enquanto que os homens em sua maioria responderam que há um processo brando de erosão. A questão P10 (Você considera o relevo e as características deste Parque sendo?), entre os sexos, mesmo que dividido, a maioria dos homens responderam que consideram o relevo ondulado. $\mathrm{Na}$ pesquisa de Bosco et al. (2004), os resultados apontaram a importância de se considerar habilidades visuoespaciais entre homens e mulheres, e identificou que a capacidade de percepção espacial nos homens sobrepõe ao das mulheres, pois os homens tendem a usar as habilidades visuoespaciais em ambientes naturais com uma maior frequência. Coluccia \& Louse (2004), constataram que os homens dentro de um espaço, podem observar rapidamente suas características que está disponível no ambiente, enquanto que as mulheres, são mais centradas e acabam tendo mais dificuldades. Assim, os homens têm um melhor desempenho de orientação espacial, porque eles acabam fazendo interpretações mais completas de acordo com as informações disponíveis.

\subsection{ANÁLISE DE CORRESPONDÊNCIA ENTRE OS SEXOS E AS QUESTÕES RELACIONADAS AO MEIO BIÓTICO.}

A FIGURA 6 apresenta a tabela de contingência entre as respostas do sexo dos entrevistados e as questões relacionadas ao meio biótico. Observa-se nessa tabela que as resposta (R1), apresentam uma alta frequência de ocorrência nas perguntas P13, P16 e P17. Nota-se também que os outros cruzamentos da tabela de contingencia apresentam uma frequência de ocorrência mais diversificados. 
Figura 2 - Tabela de contingência entre as respostas dos entrevistados e as questões relacionadas ao meio biótico.

\begin{tabular}{|c|c|c|c|c|c|c|}
\hline \multirow[b]{2}{*}{ F R1 } & P.13 & P.14 & P.15 & P.16 & P.17 & P.18 \\
\hline & 9 & $\odot$ & 0 & 0 & 8 & 랑 \\
\hline F R2 & & 0 & - & & $\bullet$ & - \\
\hline $\mathrm{FR} 3$ & & $\circ$ & * & . & & - \\
\hline F R4 & & . & 한 & & $*$ & P \\
\hline F R5 & & & - & $\cdot$ & • & $\bullet$ \\
\hline F R6 & & & * & & & \\
\hline M R1 & 0 & 랑 & (1) & 0 & 6 & e \\
\hline$M R 2$ & & 6 & $*$ & & $\circ$ & 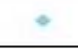 \\
\hline $\mathrm{MR}$ R & & 라 & 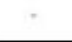 & $\circ$ & . & $=$ \\
\hline$M R 4$ & & & क & & . & P \\
\hline M R5 & & & $\circ$ & & $\circ$ & $\bullet$ \\
\hline M R6 & & & e & & & \\
\hline
\end{tabular}

Fonte: Elaborado pelos autores (2018).

Legenda: F: (Feminino); M: (Masculino); R: (Resposta); R1 (a); R2 (b); R3 (c); R4 (d); R5 (e); R6 (f).

De acordo com a TABELA 3 os autovalores das principais dimensões são:

Tabela 3 - Principais dimensões e suas inércias (autovalores) para a interação sexo e questões meio Biótico.

\begin{tabular}{cccc}
\hline $\operatorname{dim}$ & Autovalor & \multicolumn{1}{c}{$\%$} & acum\% \\
1 & 0.423482811 & 44.6 & 44.6 \\
2 & 0.340904472 & 35.9 & 80.5 \\
3 & 0.152036940 & 16.0 & 96.5 \\
4 & 0.030567698 & 3.2 & 99.7 \\
5 & 0.002815405 & 0.3 & 100.0 \\
& & \\
\hline \multicolumn{4}{c}{ Inercia total----- 0.9498073 } \\
& Chi-quadrado------ 763.65
\end{tabular}

Fonte: Elaborado pelos autores (2018).

Considerando a variação total do sistema explicada em $80,5 \%$ pelas duas dimensões principais foi possível construir o gráfico de correspondência. A estatística chi-quadrado foi de 763.65 indicando forte associação entre as linhas (sexo e respostas) com as colunas estabelecidas para o meio biótico. Observa-se no gráfico de correspondência (FIGURA 7), que as perguntas P13 (Você considera a vegetação do Parque importante para quem o frequenta?); P16 (Você acha que a fauna urbana e local são importantes para o Parque?) e P17 (Qual tipo de fauna você acha que ocorre com mais frequência no Parque?) apresentam correspondência com a resposta R1, ou seja, a letra "a" como resposta para ambos os sexos. A pergunta P14 (Em sua opinião, a quantidade e o aspecto da vegetação do Parque, apresentam-se em que estado?), independente do sexo apresenta uma correspondência com a resposta $\mathrm{R} 2$, ou seja, a letra " $\mathrm{b}$ " (se apresenta em bom estado). As outras questões apresentam uma maior diversidade de respostas. 
Figura 7 - Gráfico de correspondência entre linhas (sexo) com as colunas questões estabelecidas para o meio Biótico.

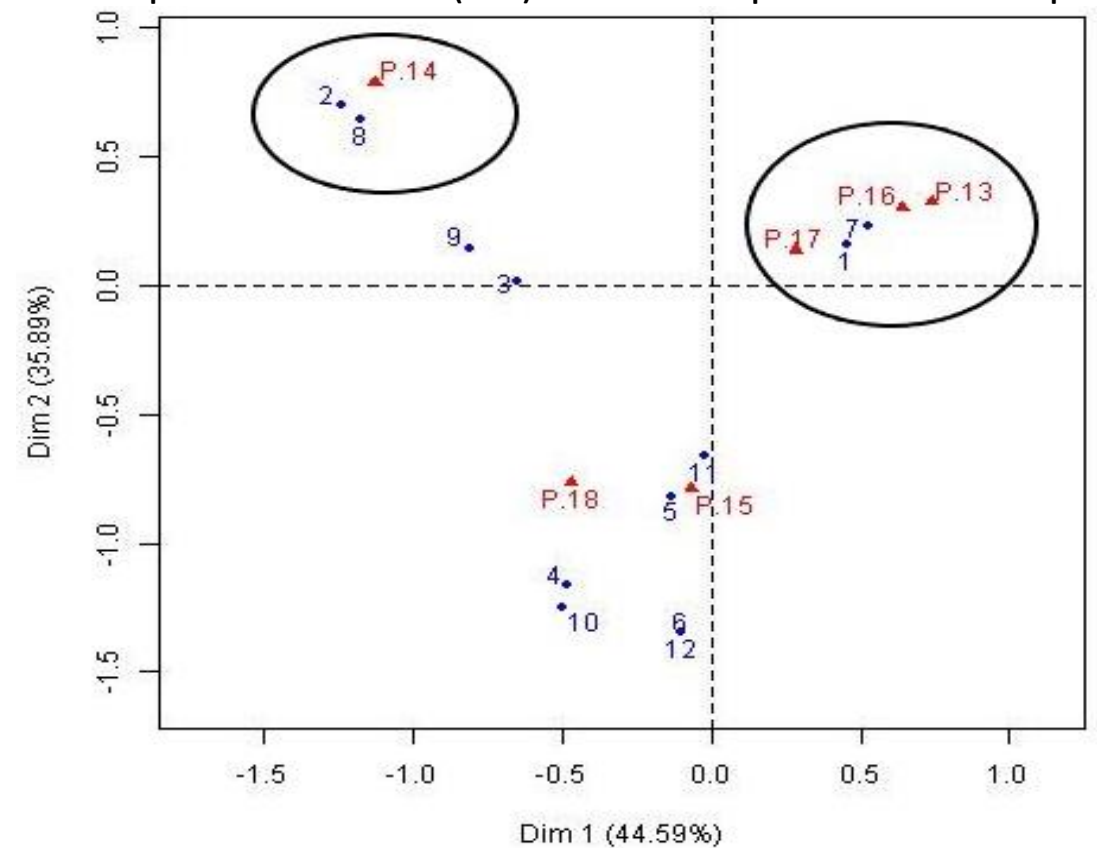

Fonte: Elaborado pelos autores (2018).

Legenda: P: (Pergunta); 1 a 6 (Sequência de respostas Feminina); 7 a 12 (Sequência de respostas Masculina).

A questão P15 (Você definiria a vegetação existente no Parque, sendo?), mesmo muito dividido, tanto os homens, quanto as mulheres em sua maioria responderam a resposta 1 , que a vegetação do parque é de mata atlântica. Na questão P18 (Dentro dos ecossistemas do parque qual chama mais a sua atenção?), as mulheres ficaram divididas entre a resposta 1 (ecossistemas terrestres) e 4 (todos), e os homens em sua maioria acreditam que todos os ecossistemas do parque the chamem mais a atenção. Elali (2009), em seu trabalho entende que o ser humano tendo uma interpretação e identificação dos elementos disponibilizados pelo ambiente, necessita concentrar sua atenção as suas feições, alternativa essa que é produto dos seus interesses e de suas formações como observador e desmembrador daquele ambiente, os quais demonstram afinidades individuais.

Desde crianças, os homens são motivados com mais frequência a explorar novos ambientes. Coluccia \& Louse (2004), explica que tais atividades, aumentam o desenvolvimento de habilidades espaciais, aumentando as diferenças entre a percepção de homens e mulheres nas observações do ambiente.

\section{CONSIDERAÇÕES FINAIS}

Constatou-se que os estudos da percepção ambiental dentro do componente sexo podem resultar na identificação das diferenças de estratégias cognitivas e do valor ecológico, mantendo ao mesmo tempo a diferenciação entre os sexos.

Considerando a metodologia aplicada e o objetivo proposto, foi possível identificar que os homens e as mulheres apresentaram semelhanças em suas respostas, no entanto, constatou-se que o sexo masculino apresentou uma melhor percepção das questões associadas com a espacialização do parque como o relevo, os processos erosivos e diferentes tipos vegetacionais encontrados no parque. 
O sexo feminino apresentou uma percepção mais sensível nas questões ligadas a gestão do parque como a falta da presença de fiscalização e de pessoas com o intuito informativo, também se constatou uma pequena diferença na percepção relativa ao tipo de ecossistema presentes no parque.

Com isso, demonstrou-se através desta pesquisa que homens e mulheres observam e analisam os parques urbanos e seu espaço geográfico em diferentes perspectivas.

\section{REFERÊNCIAS BIBLIOGRÁFICAS}

ALVES, S. M. F.; FERNANDES, P. M.; DOS REIS, E. F. Análise de Correspondência como Instrumento para Descrição do Perfil do Trabalhador da Cultura de Tomate de Mesa em Goiás. Ciência Rural, v. 39, n. 7, p. 2042-2049, 2009.

BOSCO, A.; LONGONI, A. M.; VECCHI, T. Gender Effects in Spatial Orientation: Cognitive Profiles and Mental Strategies. Applied cognitive psychology, v. 18, n. 5, p. 519-532, 2004.

BRASIL. Constituição da República Federativa do Brasil. Congresso Nacional, Brasília, 1988.

BRASIL. Diagnóstico da visitação em parques nacionais e estaduais, 2009. Disponível em www.mma.gov.br/estruturas/sbs dap/ .../diagnostico da visitacao em parques. Acesso em 19 de jul. de 2016.

BRISOLARA, S. Gender Sensitive evaluation and monitoring-Best and promising practices in engendering evaluation. USAID reviewed document. 2014.

COLUCCIA, E.; LOUSE, G. Gender Differences in Spatial Orientation: A Review. Journal of environmental psychology, v. 24, n. 3, p. 329-340, 2004.

COSTA, R. G. S.; COLESANTI, M. M. A Contribuição da Percepção Ambiental nos Estudos das Áreas Verdes. RAEGA, Curitiba, v. 22, n. 2, p. 238-251, 2011.

CRONA, B. et al. Perceptions of climate change: linking local and global perceptions through a cultural knowledge approach. Climatic change, v. 119, n. 2, p. 519-531, 2013.

DA SILVA, M. E. M.; SORIANO-SIERRA, E. J. Análise da percepção do visitante sobre a revitalização da orla marítima: o modelo do Parque Linear Calçadão, Itapema-Santa Catarina-Brasil. Revista Brasileira de Pesquisa em Turismo, v. 9, n. 1, p. 76-96, 2015

DE CARLI, B. P. et al. Caracterização do estado trófico de um lago no Parque Natural dos Esportes "Chico Mendes". In: RIBEIRO, A. I. et al. (Org). Memórias do II Workshop Integração de Saberes Ambientais. Sorocaba: UNESP, 2017. p. 94-97.

DE CARLI, B. P. et al Comunidade de invertebrados bentônicos em um lago do Parque Natural dos Esportes "Chico Mendes". In: RIBEIRO, A. I. et al. (Org). Memórias do II Workshop Integração de Saberes Ambientais. Sorocaba: UNESP, 2017. p. 88-93.

DE LUCENA, M. M. A.; FREIRE, E. M. X. Percepção ambiental sobre uma Reserva Particular do Patrimônio Natural (RPPN), pela comunidade rural do entorno, semiárido brasileiro. Educação Ambiental em Ação. v. 35, 2011.

ELALI, G. A. Relações Entre Comportamento Humano e Ambiência: Uma Reflexão com Base na Psicologia Ambiental. Anais do Colóquio Ambiências Compartilhadas. Rio de Janeiro: ProArq-UFRJ, 2009. p. 1-17.

GARCIA-CERVANTES, L. et al. Perceived environment in relation to objective and self-reported physical activity in Spanish youth. The UP\&DOWN study. Journal of sports sciences, v. 34, n. 15, p. 1423-1429, 2016.

JABBOUR, C. J. C.; SANTOS, F. C. A.; NAGANO, M. S. Análise do relacionamento entre estágios evolutivos da gestão ambiental e dimensões de recursos humanos: estado da arte e survey em empresas brasileiras. Revista de Administração da Universidade de São Paulo, v. 44, n. 4, 2009.

KASSAMBARA, A.; MUNDT, F. factoextra: Extract and Visualize the Results of Multivariate Data Analyses. 2017. R package version 1.0.5. https://CRAN.R-project.org/package=factoextra. Acesso em 14 de novembro de 2017. 
MORAES, T. C. A. de. Análise da Percepção Ambiental na Comunidade Apiques (Itapipoca/CE): Um Enfoque de Gênero. Dissertação (Mestrado em Desenvolvimento e Meio Ambiente) - Universidade Federal do Ceará. Fortaleza, p. 102. 2012.

NENADIC, O.; GREENACRE, M. Computation of multiple correspondence analysis, with code in R. 2005.

PARDUE, M. et al. Exploring the Biological Contributions to Human Health: Does Sex Matter? National Academies Press, 2001.

PINA, J. H. A.; DOS SANTOS, D. G. Qualidade ambiental e de vida: Uma análise qualitativa do Parque do Sabiá em Uberlândia-MG. Caminhos de Geografia, v. 10, n. 31, 2009.

RICHTER, M.; BÖCKER, R. Developing an urban landscape management concept through the integration of environmental quality goals and environmental information systems. In: Urban Ecology. Springer, Berlin, Heidelberg, 1998. p. 479-481.

RODRIGUES, M. L.; et al. Percepção Ambiental Como Instrumento de Apoio na Gestão e na Formulação de Políticas Públicas Ambientais. Saúde Soc. São Paulo, v.21, supl.3, p.96-110, 2012.

SANTOS, L. G. et al. Comunidade fitoplanctônica e zooplanctônica no lago artificial do Parque Natural dos Esportes "Chico Mendes" - Sorocaba/SP. In: RIBEIRO, A. I. et al. (Org). Memórias do II Workshop Integração de Saberes Ambientais. Sorocaba: UNESP, 2017. p. 98-103.

SILVA, Y. V. et al. Análise de correspondência: uma abordagem geométrica. 2012.

SNEIDER, J. T. et al. Sex Differences in Spatial Navigation and Perception in Human Adolescents and Emerging Adults. Behavioural processes, v. 111, p. 42-50, 2015.

STHDA, Statistical Tools for High-throughput Data Analysis in. Disponível em: http://www.sthda.com/english/articles/31principal-component-methods-in-r-practical-guide/120-correspondence-analysis-theory-and-practice. Acesso em 14 de novembro de 2017.

STHDA, Statistical Tools for High-throughput Data Analysis in. Disponível em: http://www.sthda.com/english/wiki/factoextra-r-package-easy-multivariate-data-analyses-and-elegant-visualization. Acesso em 14 de novembro de 2017.

VICENTE-MOLINA, M. A.; FERNÁNDEZ-SAINZ, A.; IZAGIRRE-OLAIZOLA, J. Does gender make a difference in proenvironmental behavior? The case of the Basque Country University students. Journal of Cleaner Production, v. 176, p. 8998, 2018.

XIAO, Chenyang; MCCRIGHT, Aaron M. Gender differences in environmental concern: Revisiting the institutional trust hypothesis in the USA. Environment and Behavior, v. 47, n. 1, p. 17-37, 2015.

WEISS, E. M. et al. Sex Differences in Cognitive Functions. Personality and individual differences, v. 35, n. 4, p. 863-875, 2003.

YANG, Y. C. E. et al. Gendered Perspectives of Ecosystem Services: A Systematic Review. Ecosystem Services, v. 31, p. 58-67, 2018. 